\title{
High prevalence of HIV/HTLV co-infection in Porto Alegre, Southern Brazil
}

\begin{abstract}
Background: HIV/HTLV co-infection rates in Brazilian cities were $1.5 \%$ to $10 \%$ in São Paulo, $5.7 \%$ in Rio de Janeiro and $20 \%$ in Salvador. The aim of this study was to determine the prevalence of HIV/HTLV co-infection in patients undergoing treatment at the STD/HIV Specialized Healthcare Provider of the City of Porto Alegre.

Methodology: This is a prevalence study, with a sample of 1741 HIV-positive patients. The ELISA method using the HTLV-Murex HTLV 1 and 2 kit (Murex Biotech Ltd) was employed for serum antibody analysis for HTLV 1/2, in addition to the Western Blot method using the HTLV Blot 2.4 kit (Gene labs Diagnostics, Singapore). The SPSS program 14.0 version was used for data analysis. Chi-square test was used to assess the categorical variables and $\mathrm{p}<0.05$ was considered significant.
\end{abstract}

Results: The rate of HIV/HTLV co-infection was $13.1 \%$ (95\% CI: 11.6 to 14.6). Of the 137 patients tested, 62 (45.3\%) were HTLV 1, 39 (28.5\%) were HTLV 2, 11 (8\%) were HTLV 1 and 2, $10(7.3 \%)$ were HTLV $1 / 2,12$ were indeterminate $(8.8 \%)$, and $3(2.2 \%)$ were negative. The most prevalent type of HTLV virus was HTLV $1(\mathrm{P}=0.028)$.

Keywords: HIV, HTLV, Co-infection, Lymphotropic, Genomes, Inflammatory
Volume 5 Issue 7 - 2017

\author{
Cynara Carvalho Nunes, ${ }^{2}$ Eduardo \\ Steintresser,' Isabel Lamego, ${ }^{2}$ Isabela Osorio \\ de Freitas, ${ }^{2}$ Jessica Bianchessi ${ }^{2}$ \\ 'Central Laboratory of Laboratorio Central do Centro de \\ saude Vila dos Comerciarios (CSVC), Brazil \\ ${ }^{2}$ Specialized Healthcare Provider of the City of Porto Alegre, \\ Servico de Assistencia Especializada em DSTs/HIV da Prefeitura \\ de Porto Alegre (SAE/PMPA), Brazil
}

\begin{abstract}
Correspondence: Cynara Carvalho Nunes, Specialized Healthcare Provider of the City of Porto Alegre, Rua Henrique Dias, 194/204-Bairro Bom Fim, Porto Alegre-RS, CEP: 90035-100-Brazil, Email cynara_infectologia@terra.com.br
\end{abstract}

Received: November 13, 2017 | Published: December 01, 2017
Abbreviations: HTLV, Human T-lymphotropic Virus; HIV, Human Immunodeficiency Virus; ELISA, Enzyme-Linked Immuno Sorbent Assay

\section{Introduction}

Type 1 and type 2 human T-cell lymphotropic viruses (HTLV-1 and HTLV- 2) were the first retroviruses described, in 1979 and 1981, respectively. ${ }^{1}$ HTLV- 1 and 2 viruses share $60 \%$ of their genomes. ${ }^{2}$ Despite the fact that most individuals infected by these viruses remain asymptomatic throughout life, it is known that these agents are responsible for clinical neoplastic, inflammatory or degenerative syndromes, and HTLV-2 poses lower risk for the development of pathologies. $.^{1-4} \mathrm{HIV}-1$ virus was discovered in 1983, and it was considered the etiological agent of the Acquired Immunodeficiency Syndrome in $1984 .{ }^{1}$ Retroviruses display tropism for cytotoxic T-cells CD4 and CD8. While the HTLV 1 and HIV-1 viruses show tropism primarily for CD4+ T-cells, HTLV-2 displays tropism for CD8+ T-cells. It is known that HTLV-1 and 2 viruses infect about 10-20 million individuals worldwide, whereas HIV virus infects sixty million individuals. ${ }^{3}$ Regions with higher prevalence of HTLV-1 are the southwestern area of Japan, the Caribbean, Central and South America, Melanesia, and Africa. ${ }^{5,1}$

The HTLV-2 virus, on the other hand, shows higher prevalence in regions and indigenous groups of North America, Central and South America, Pygmies in Central Africa, and Mongols in Asia, besides injectable drug users in the United States, Italy, and Vietnam. ${ }^{1}$ In South America, the countries with documented prevalence of HTLV are Colombia, Brazil, Peru, Chile, and Argentina. ${ }^{1}$ In Brazil, infections by the HTLV-1 and 2 were initially evidenced among the Yeoman Indians and Japanese immigrants living in the state of Mato Grosso do Sul. ${ }^{5}$ In the general population, seroprevalence was evaluated in blood donors, and the following prevalence have been described: 0.42 to $0.78 \%$ in the city of Rio de Janeiro, $0.15 \%$ in the city of São Paulo, $1.35 \%$ in the city of Salvador, and $1.56 \%$ in the city of Porto Alegre. ${ }^{5,6}$
Based on various studies, it is estimated that there are approximately 750 thousand individuals infected with the HTLV in Brazil. ${ }^{5}$

The HIV-1 and HTLV-1 and 2 viruses share the same transmission routes ${ }^{1,5,6}$ and HTLV-1 and HTLV-2 have co-infected HIV-1 infected individuals in 2 to $20 \%$ of cases. ${ }^{1}$ Co-infection with HIV and HTLV-2 predominates in Europe and the United States of America (USA), while co-infection with HIV and HTLV-1 is more frequently reported in South America and Africa. ${ }^{1,3,5}$ In Brazil, the prevalence of co-infection was evaluated in several Brazilian cities, and seroprevalence was 1.5 to $10 \%$ in São Paulo. ${ }^{7,8} 4 \%$ in Belém ${ }^{9} 5.7 \%$ in Rio de Janeiro, ${ }^{10}$ and $20 \%$ in Salvador. ${ }^{11}$ Considering that there is no study on the prevalence rate of HIV/HTLV co-infection in the city of Porto Alegre, this study has the main objective of determining the prevalence of HIV/HTLV co-infection among of the City of Porto Alegre. It is important to point out that, in the context of co-infection by the HIV-1, and HTLV1 and 2 viruses, there are still other not yet clarified issues in local literature that will be evaluated, such as the most frequent risk route of transmission, demographic, clinical, and laboratory features of these patients. Therefore, this study may contribute to demonstrating the need to include anti-HTLV testing in routine lab tests ordered for HIVpositive patients who initiate follow-up at healthcare services of the city of Porto Alegre.

\section{Patients and methods}

This is a retrospective prevalence study, conducted at the STD/ HIV Specialized Healthcare Service of the City of Porto Alegre (SAE/PMPA). Based on an estimate of HIV/HTLV co-infection of approximately $2 \%$ and a margin of error of approximately $0.7 \%$, with alpha equal to 0.05 ( $95 \%$ CI), a sample size of 1741 HIV-positive patients was calculated. At this facility, the anti-HTLV ELISA test is offered to patients who begin follow-up for HIV. Thus, the study included HIV-positive patients who underwent ELISA tests for HTLV between May 1996 and December 2004. A form prepared using the EPIDATA program was designed for data collection (clinical, laboratorial, demographic variables) from patient charts. 
As to the lab methods used, initial blood draws were performed and the samples were stored at- $20^{\circ}$ Celsius until analysis. Serum HTLV 1/2 antibody detection was carried out using an ELISA technique, with the HTLV-Murex HTLV-1 and 2 kit (Murex Biotech Limited), and using Western Blot with the HTLV Blot 2.4 kit (Gene labs Diagnostics, Singapore). Criteria for interpretation are shown in (Table 1). A databank was formatted on Excel software and posteriorly exported to the SPSS program (14.0 versions) for data analysis. Categorical variables were described by absolute frequency and relative percentage frequency. Quantitative variables were described by mean and standard deviation when symmetrical and median and inter quartile interval when asymmetrical. Categorical variables were compared with the Chi squared test with Yates' correction, and quantitative variables among the groups with Student's t test for independent samples when symmetrical and the Mann Whitney test when asymmetrical. A p value of less than 0.05 was considered significant. The study was approved by the Ethics Committee of Hospital Presidents Vargas.

Table I Western blot interpretation criteria

\begin{tabular}{|c|c|}
\hline Standard & Band identified \\
\hline HTLV-I & p19 and/or p24 +gd2I + rgp46-I \\
\hline HTLV-2 & p19 and/or p24 + gd2I + rgp46-II \\
\hline HTLV-I and HTLV-2 & $\mathrm{p} 19$ and/or p24 +gd2I +rgp46-I + rgp46-II \\
\hline HTLV-I/2 - not typed & $\mathrm{p} 19$ and/or $\mathrm{p} 24+\mathrm{gd} 21$ \\
\hline Indeterminate & Any combination of the bands do not described above \\
\hline Negative & Absence of bands \\
\hline
\end{tabular}

\section{Results}

Initially, 1741 patients who sought the STD/HIV Specialized Healthcare Service of the City of Porto Alegre between May 1996 and December 2004 were tested for anti-HTLV Elisa. Of these, 255 were reagent, revealing a $14.7 \%$ prevalence of co-infection. However, of these 255 individuals, only 137 were tested with Western blot. Considering that confirmation by Western blot was made in $89.1 \%$ $(122 / 137)$ of the cases, the prevalence of co-infection was adjusted to $13.1 \%$ (95\% CI: 11.6 - 14.6). In the sample studied $(n=137), 91.2$ $\%$ resided in Porto Alegre and the majority white (58.4\%). The male/ female ratio was $1.5: 1$, and the most common exposure risk factors were use of injectable drugs $(50.4 \%)$, heterosexual relationship (18.2\%), and homo/bisexual exposure (12\%). As to the stage of HIV infection at screening for HTLV, $21.9 \%$ were asymptomatic and $62 \%$ had a diagnosis of AIDS. In the patients who used antiretroviral (73\%), the criterion for initiating antiretroviral therapy was a CD4 count below 350 or the presence of an AIDS-defining disease as per CDC 97 criteria in $60 \%$ of them. In $37 \%$ of the patients, this information was not available. (Table 2) shows the distribution of HTLV types found. HTLV-1 was most prevalent type followed by HTLV-2 ( $\mathrm{P}=0.028)$.

Table 2 Prevalence of double HTLV/HIV infection*

\begin{tabular}{ll}
\hline Types of HTLV No. (\%) & $\mathbf{n = ~ I 3 7 ~}$ \\
\hline HTLV-I & $62(45.3)$ \\
HTLV-2 & $39(28.5)$ \\
HTLV-I and 2 & $1 \mathrm{I}(8.0)$ \\
HTLV-I/2 & $10(7.3)$ \\
Indeterminate & $12(8,8)$ \\
Negative & $3(2.2)$ \\
Total & $137(100)$
\end{tabular}

*Data are presented as number and percentage

Injectable drug use was the factor most associated with transmission among men, where 48 out of 52 males $(98,3 \%)$ were injectable drug users $(p<0,001)$. On the other hand eighteen of 31 women $(59 \%)$ related heterosexual exposition $(\mathrm{p}<0,001)$. There were no statistically significant differences in the assessment of an association between age at the time of the anti-HTLV test, ethnic group, gender, nadir of CD4T+ cell counts, and the types of HTLV 1 and 2 (Table 3 ) Of the $122 \mathrm{HIV} /$ HTLV-reagent patients, it was noted that $93(76.2 \%)$ were reagent for anti-HCV. No association was found between gender, race/ethnic group, and triple positive serology, ( $\mathrm{p}=0.075$ and 0.607 , respectively). However, an association was identified between injecting drug use and positive serology for HIV, HTLV, and HCV (Table 4).

Table 3 Demographic and clinical characteristics among HIV/HTLV I and 2 patients*

\begin{tabular}{|c|c|c|c|}
\hline Characteristics & HTLV-I $n=62 \%$ & HTLV-2 n=39\% & $\mathbf{P}$ \\
\hline Age (years) & $37.3 \pm 9.7$ & $36.9 \pm 9.4$ & 0.83 \\
\hline \multicolumn{4}{|l|}{ Gender No. (\%) } \\
\hline Male & $39(62.9)$ & $22(56.4)$ & 0.66 \\
\hline \multicolumn{4}{|c|}{ Ethnic Group No. (\%) } \\
\hline White & $34(55.7)$ & $23(59.0)$ & \multirow{3}{*}{0.77} \\
\hline Black & $21(34.4)$ & II (28.2) & \\
\hline Brown [pardo] & $6(9.8)$ & $5(12.8)$ & \\
\hline \multicolumn{4}{|c|}{ Exposure Factor No. (\%) } \\
\hline IDU & $30(66.7)$ & $21(80.8)$ & \multirow{2}{*}{0.32} \\
\hline Heterosexual & $15(33.3)$ & $5(19.2)$ & \\
\hline CD4 count cell & 288 (22I to 496$)$ & 274 (225 to 305.5 ) & 0.28 \\
\hline
\end{tabular}

*Data are presented with number (percentage), mean \pm standard deviation, or median (interquartile interval, percentile 25,75 ).

IDU: Injectable Drug Users

Table 4 Prevalence of triple infection (HIV/HTLV/HCV) and associated factors*

\begin{tabular}{|c|c|c|c|}
\hline \multicolumn{2}{|c|}{ HIV/HTLV (n=|22) } & \multicolumn{2}{|c|}{ HIV/HCV/HTLV $(n=93)$} \\
\hline Characteristic & $\mathbf{n}$ & No (\%) & $\mathbf{P}$ \\
\hline \multicolumn{4}{|l|}{ Gender } \\
\hline Male & 74 & $61(82.4)$ & \multirow{2}{*}{0.075} \\
\hline Female & 48 & $32(66.7)$ & \\
\hline \multicolumn{4}{|c|}{ Race/Ethnic Group } \\
\hline White & 70 & $56(86 \%)$ & \multirow{3}{*}{0.607} \\
\hline Black & 35 & $25(7 \mathrm{I} .4 \%)$ & \\
\hline Brown [pardo] & 16 & $12(75.0)$ & \\
\hline \multicolumn{4}{|l|}{ Risk Factors } \\
\hline IDU & 61 & $58(95.1)$ & \multirow{2}{*}{$<0.001$} \\
\hline Heterosexual & 22 & I2(54.5) & \\
\hline
\end{tabular}

*Data are presented as number and percentage

\section{Discussion}

At the time of the study, Porto Alegre had a population of $1,373,313$ inhabitants, and was the third city in Brazil in number of AIDS cases. ${ }^{12}$ According to the Epidemiological Bulletin of the Health Secretariat of Porto Alegre published in 2003, the total number of AIDS cases was 15,301 , and the male: female ratio was $1: 1.5$, with the predominance of heterosexual exposure $(60.4 \%)$, followed by the use of injectable drugs $(16 \%)$ and homo/bisexual behavior $(13 \%) .{ }^{13} \mathrm{HIV}$ exposure characteristics in this city follow the trend for feminilization also described among other Brazilian states. ${ }^{14}$

The HIV/HTLV viruses are frequently co-pathogens in various countries. In the United States, several studies have demonstrated a high prevalence of co-infection, reaching 16\% in New York and 8.4\% in New Orleans. ${ }^{1,19}$ In Africa, recent studies in Guinea-Bissau point to a high prevalence of HIV/HTLV-1 virus co-infection $(7.1 \%){ }^{3}$ In 
the Caribbean island of Martinique, the prevalence of co-infection is $9.4 \% .{ }^{15}$ To date, few studies have evaluated the prevalence of HIV/ HTLV co-infection in the southern region of Brazil. In some urban areas of Brazil, indices of co-infection among individuals infected by HIV-1 were $1.5 \%-10 \%$ in São Paulo, ${ }^{7,8} 7.4 \%$ in Belém, ${ }^{2} 5.7 \%$ in Rio de Janeiro, ${ }^{10}$ and $20 \%$ in Salvador. ${ }^{11}$ In our study, a $13.1 \%$ (95\% CI: 11.5 - 14.6) prevalence rate of HIV-HTLV co-infection was obtained, the second higher prevalence in Brazil. In a study conducted at the Dermatology Service of the state of Rio Grande do Sul, 105 HIVpositive patients with dermatological manifestations were evaluated, with a $12.5 \% \mathrm{HIV} / \mathrm{HTLV}-1$ co-infection rate. ${ }^{16}$

HIV/HTLV-1 co-infection was the most prevalent $(\mathrm{P}=0.028)$ however there was a high frequency of HTLV-2, which is not found in other Brazilian states, such as Bahia and São Paulo, with a high prevalence of HTLV/HIV co-infections. ${ }^{7,8,11}$ In a cohort study to asses progression of HIV-1 infection carried out at Hospital Clementine Fraga Filho (state of Rio de Janeiro), 473 patients were tested for HTLV: 27 (5.7\%) were HTLV-1, two were HTLV-2, and 1 showed double reactivity..$^{10}$ Interesting, a recent study conducted in districts near the city of Salvador identified a cosmopolitan subtype of the HTLV-1 of African origin. ${ }^{17}$ Whereas another study conducted among Guarani Indians in the state of Paraná identified a high prevalence of HTLV-2, thus emphasizing the diversity of HTLV in Brazil. ${ }^{18}$

The co-existence of HIV/HTLV in the same areas and shared transmission routes facilitates simultaneous infection by these human retroviruses. Injectable drug users, who share needles and syringes paraphernalia, represent subpopulations with the higher prevalence. ${ }^{1}$ In Japan, co-infection is also prevalent in hemophilic patients. ${ }^{15}$ Researches carried out in some cities of world investigating the prevalence of HIV/HTLV co-infection among injecting drug users showed different rates, such as $8,4 \%$ in New Orleans/USA and $20 \%$ in Salvador/Brazil. Approximately $50 \%$ of the patients in our study were of injecting drug users. We noted that the use of injectable drugs was the factor most associated with transmission among men $(p<0.001)$; whereas the heterosexual route of contamination was more common among women $(p<0.001)$. It is important to note that sexual transmission of the HTLV is four times more effective from man to woman than vice versa, specially associated with genital ulcers from other sexually transmitted diseases such as syphilis and herpes. ${ }^{1,4,15}$

It hás been reported a high prevalence of co-infection by HTLV- 2 among injectable drug users in the USA, ${ }^{1,19}$ whereas in Guinea- Bissau or Peru, there is a high prevalence of HTLV 1 associated with sexual exposure. ${ }^{3,15}$ However, we did not find any statistically significant differences between the exposure factor and infection among the types of HTLV-1 and. ${ }^{1}$ The coexistence of both HTLV- 1 and 2 viruses in the city of Porto Alegre described for the first time raises issues related to gender and race/ethnic group, which are yet to be elucidated. In this study, there were no statistically significant differences between ethnic groups or gender in relation to the prevalence of HTLV 1 or 2.

Studies conducted in patients co infected with HIV/HTLV have shown that clinical progression may be different from that observed among patients with HIV-1 mono infection. Differences in methodology and in the populations studied may explain the great variation in the results obtained, from an apparently protective effect to acceleration of diseases progression associated to HTLV-1, HTLV-2, and HIV-114. In Brazil, HIV/HTLV-1 coinfection has been associated with a higher CD4 count despite a greater progression of HIV infection. ${ }^{5,9,10}$ These data demonstrate that the higher CD4 lymphocyte count does not promote an immune protection and may be related to non-specific proliferation of lymphocytes induced by HTLV-1.
These results seem to suggest that the cut-off point in making clinical therapeutic decisions in HIV-1 infection may be inappropriate in face of HTLV co-infection, blurring the ideal moment for introduction of antiretroviral medication and prophylaxis against opportunistic infections. Issues related to the pre-treatment drop in CD4 count among co infected patients receiving antiretroviral treatment are still under evaluation in studies performed at our facility. 76.2\% (93) of the patients tested were anti HCV positive. Upon evaluation of the association between gender, race/ethnic group, and triple positive serology, no association was found. Therefore, it was noted that the use of injectable drugs was the factor most associated with the presence of positive serology for infection by viruses HIV 1 , HTLV, and HCV.

Conversely, 54\% of heterosexual patients showed evidence of triple infection. It has been recognized that individuals infected by HIV display a higher prevalence of infection by $\mathrm{HCV}$ than the general population. The higher prevalences of HIV/HCV co-infection are seen in studies that include injectable drug users, which is in agreement with our study. Conversely, infection by the HIV-1 virus has an impact on infection by the HCV virus, leading to an even higher Viremia and consequently, a higher risk for sexual transmission. ${ }^{20,21}$ This is consistent with data found in the present study, in which $54 \%$ of heterosexual patients were infected with HIV, HCV, and HTLV. In summary, we described here a high prevalence rate of HIV/HTLV 1 and an unprecedented prevalence of hand HIV/HTLV-2 co-infection in this Brazilian location, showing the need to include anti-HTLV testing in the routine of tests ordered for HIV-positive patients who initiate medical follow-up.

\section{Acknowledgements}

The present study was conducted with the authors' personal resources.

\section{Conflicts of interest}

None.

\section{References}

1. Mandell, Douglas, and Bennets, Principles and Practice of infectious diseases, Philadelphia-Elsevier, Churchill Livingstone. 2005;165:2098-2105.

2. Vallinoto AC, Azevedo VN, Santos DE, et al. Serological evidence of HTLV-I and HTLV-2 coinfections in HIV-1 positive patients in Belém, state of Pará, Brazil. Mem Inst Oswaldo Cruz. 1998;93(3):407-409.

3. Holmgren B, Silva Z, Larsen O, et al. Dual infections with HIV-1,HIV-2 and HTLV 1 are more common in older women than in men in GuineaBissau. AIDS. 2003;17(2):241-253.

4. Manns A, Hisada M, La Grenade L. Human T-lymphotropic virus type I infection. Lancet. 1999;353: 1951-1958.

5. Brasil, Ministério da Saúde. Secretaria de Vigilância em Saúde. Programa Nacional de DSTs e AIDS. Boletim epidemiológico. 2003;17(1).

6. Veronesi Tratado de infectologia, Ricardo Veronesi, Roberto Focaccia São Paulo, Atheneu, Brazil, pp. 1997;402-408.

7. Casseb J, Caterino-de-Araujo A, Hong MA, et al. Prevalence of HTLV-I and HTLV-1I infections among HIV infected asymptomatic individuals in Sao Paulo, Brazil. Rev Inst Med Trop Sao Paulo. 1999;39(4):213-215.

8. Caterino-de-Araujo A, Favero A, de los Santos-Fortuna E, et al HTLV-I/HTLV-II coinfection in an AIDS patient from Sao Paulo, Brazil. AIDS Res Hum Retroviruses. 2000;16(18):715-719. 
9. Schecter M, Moulton L, Harrison L. HIV viral load and CD4 lymphocyte counts in subjects coinfected with HTLV-1 and HIV 1. Journal of acquired Immune deficiency syndromes and human Retrovirology. 1997;15(4):308-311.

10. Schecter M, Harrison L Halsey N, et al. Coinfection with Human T-cell lymphotropic virus Type 1 and HIV in Brasil. JAMA. 1994;271(5):353-357.

11. Brites C, Harrington Jr WJ, Pedroso C, et al. Epidemiological characteristics of HTLV-I and II coinfection in Brazilian subjects infected by HIV-1. Braz J Infectious Dis. 1197;1(1):43-48.

12. Ministério da saúde Brazil. Secretaria de Vigilância em saúde. Programa nacional de DSTs e AIDS. Guia de Manejo Clínico do paciente com HTLV, Brazil. 2004;p.1-4.

13. Boletim epidemiológico. Secretaria Municipal de Saúde de Porto Alegre. Ano IX. 2007:34.

14. Ministério da saúde Brazil. Boletim epidemiológico AIDS-Ano IV n ${ }^{\circ} 1-$ julho a dezembro de 2006/ janeiro a junho de, Brazil. 2007.

15. Chavance M, Neisson-Vernant C, Quist D, et al. HIV/HTLV-I coinfection and clinical grade at diagnosis. J Acquir Immune Defic Syndr Hum Retrovirol. 1995;8(1):91-95.
16. Bonamigo RR, Borges K, Rietjens J, et al. Human T lymphotropic virus 1 and hepatitis $\mathrm{C}$ virus as risk factors for inflammatory dermatoses in HIV-positive patients. Int J Dermatol. 2004;43(8):568-570.

17. Rego FFA, Alcantara LCJ, Neto JPM, et al. HTLV type 1 Molecular Study in Brazilian Villages with African Characteristics Giving Suport to the Post-Columbian Introduction Hypotesis. Aids Research and Human Retroviruses, 2008;24(5):673-677.

18. Barreto MM, Bender AL, Bonatto SL, et al. Human T-cell lynphotropic vírus type II in Guarani Indians, Southern Brazil. Cad Saude Publica. 2005;21(6):1947-1951.

19. Bessinger R, Beilke M, Kissinger P, et al. Retroviral coinfections at a New Orleans HIV outpatient clinic. J Acquir Immune Defic Syndr Hum Retrovirol. 1997;14(1):67-71.

20. Ministério da Saúde Brasil. Secretaria de Vigilância em Saúde. Programa Nacional de DSTs e AIDS. Recomendações para terapia antiretroviral em adultos e adolescentes infectados pelo HIV 2007, Brazil, pp.2007.1-229.

21. Zehender G, Colasante C, Santambrogio S, et al. Increased risk of developing peripheral neuropathy in patients coinfected with HIV-1 and HTLV-2. J Acquir Immune Defic Syndr. 2002;31(4):440-447. 